\title{
KNOWLEDGE AND PRACTICE OF UNDERSTANDING PLAGIARISM BY STUDENTS FROM BAQAI MEDICAL UNIVERSITY
}

\author{
Syed Zubairuddin Ahmed ${ }^{1}$, Fatima Ahmad², Muhammad Sabih Merchant ${ }^{3}$, Muhammad Ashraf Nazir ${ }^{4}$ \\ ${ }^{1,4}$ Lecturer, College of Dentistry, University of Dammam, Saudi Arabia \\ ${ }^{2,3}$ Assistant Professor, College of Dentistry, Baqai Medical University, Pakistan \\ Correspondence: Syed Zubairuddin Ahmed, Email: mrzubs@hotmail.com
}

\begin{abstract}
Background: Plagiarism is the theft of intellectual property with lack of source acknowledgment. The objective of this study was to determine the information regarding Baqai Medical University student's exposure about knowledge, attitude and practices and their awareness of the repercussions and the policies, systems and procedures of the BMU regarding plagiarized matter.

Methods: A study for duration of 6 months was conducted in Baqai Medical University where volunteers answered questionnaires anonymously. There were following four sections in the questionnaire: (a) demographic data, such as gender, level of education; (b) five questions regarding knowledge; (c) five questions regarding practice; and (d) five questions regarding policies, awareness and outcomes.

Results: The sample size of the study was 150 participants, among which 61 were males and 89 females, with 70 BDS students, 50 MBBS students and 30 House officers. Overall, $90 \%$ of the participants were aware of the meaning of plagiarism. Approximately $20 \%$ of the participants were not aware of the standard referencing criteria. $88 \%$ of the correspondents considered continuous assessments to improve their writing skills. When asked on how the students believed to improve their skills and avoid plagiarism. Majority of the participants $(75.3 \%)$ considered time ample enough to work with almost equal correspondence among males and females. $81.3 \%$ of the students reported lack plagiarism workshop. $82.7 \%$ of the respondents agreed to the consequences of plagiarism. Nevertheless, both males $(72.1 \%)$ and females $(73 \%)$ ) equally shared their work with friends before submission. Even though $68 \%$ of them were aware of the college / university policies, systems and procedures for involving plagiarism, men exhibited an increased awareness ratio $(70.5 \%)$ as compared to females $(66.3 \%)$.

Conclusion: With the help of this questionnaire, the knowledge, attitude, and practice of the BMU students was determined regarding plagiarism. In the end, recommendations for such type of studies in the future were also provided.
\end{abstract}

Keywords: Plagiarism, knowledge, practice, policies, questionnaire, medical education, Pakistan

\section{Introduction}

Plagiarism is the theft of intellectual property with lack of source acknowledgment (1). In the field of biomedical writing, plagiarism is considered a grave academic and an ethical transgression which has now been acknowledged as a wide spread crisis and requires immediate attention (2). The components of intellectual theft consist of stealing ideas, reports, presentations, matter from science and literature, and coursework (3). For the past one decade, an increase in the amount of manuscripts with plagiarism has been seen, but mostly developed nations are working on this issue as their undergraduate students undergo research training (4). Moreover, the developed countries are also provided with better training, superior research environment, and availability of software for detection of plagiarism (5). Even though, it is not easy to determine the prevalence of plagiarism but this phenomenon can be better understood by conducting investigations on the attitudes of the participants (6). According to "theory of planned behavior", certain attitudes and subjective norms are responsible for behavior change. There can be multiple reasons for getting involved in academic misconduct of plagiarism include ferocious competitive academic environment, external pressure, poor time management, and the impractical deadlines (7-10). Therefore, there is an ardent need of educational reforms and policies to prevent plagiarism at both university and college level (11).

Steen et al. (12) reported an increase in the acknowledgment and retraction of plagiarized articles based on 2,047 articles from Pub Med indexed journals. When it comes to Pakistani medical students, (13) conducted a survey on academic theft and observed that an increased number of medical students were not only implicated in copying word to word data from the internet, senior peers, and class mates with or without their permission but were also caught up with making up 
false data to exhibit favorable results.

Even though, it is not easy to determine the prevalence of plagiarism, but this phenomenon can be better understood by conducting investigations on the attitudes of the participants, as Ajzen believed in his theory of planned behavior that humans are based on reasons, i.e. prior to a certain behavior taking place, certain attitudes and subjective norms are responsible (14). Therefore, there is an ardent need of educational reforms and severe policies at both university and lower grade level.

Therefore, the aims of the current study were; to explore the attitudes and to encourage proper training of both Pakistani medical and dental students towards plagiarism.

\section{Methodology}

A study based on a questionnaire was conducted in Baqai Medical University, Karachi on not only medical and dental students but also dental house officers for the duration of 6 months.

The questionnaire consisted of 15 comprehensive questions which were specifically designed to determine the knowledge, practice and attitude of participants regarding various forms of plagiarism and its consequences.

By employing a uniform system, two of the authors distributed the questionnaire to random medical and dental students once the regularly scheduled classes ended. Once the aims and objectives of the study were explained, a verbal informed consent was obtained, and the participants were given ample time to fill out the complete form. Similarly, house officers were also surveyed with the same methodology. To encourage truthful responses, the participants were taken into confidence and guaranteed total anonymity with record of only their area of expertise. The Ethical Review Boards of Baqai Dental College reviewed and approved the research.

\section{Results}

From the total number of volunteers of the study, there were $41 \%$ males and $59 \%$ females, $23 \%$ were house officers, and $77 \%$ were students, of which $56.5 \%$ were BDS students and $43.5 \%$ were MBBS students. Since there were a total of 15 questions on the questionnaire,

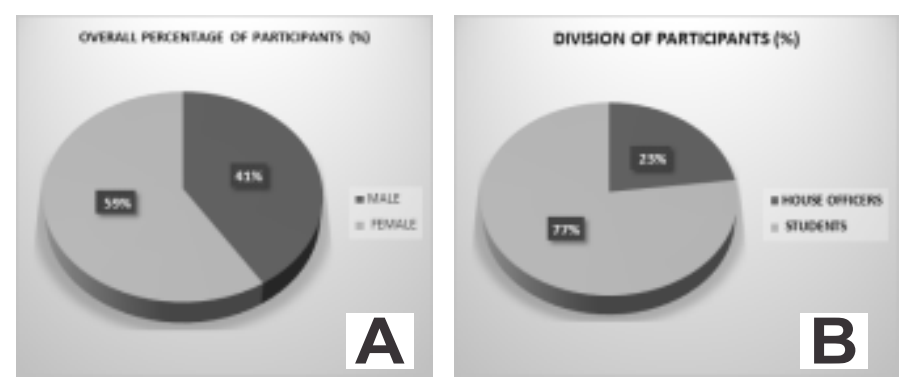

hence the results will also be divided based on their sub headings.

Figure 1: Pie A showing division of participants between male and female participants and B showing division between house officers and students

\section{Knowledge}

Overall, $90 \%$ of the participants were aware of the meaning of plagiarism among which females had more awareness $(91 \%)$ as compared to men $(88.5 \%)$, however, when it came to understand that this practice is wrong, men agreed more $(88.5 \%)$ as compared to females (79.8\%). Approximately $20 \%$ of the participants were not aware of the standard referencing criteria incorporation into one's work. $88 \%$ of the correspondents agreed that the continuous

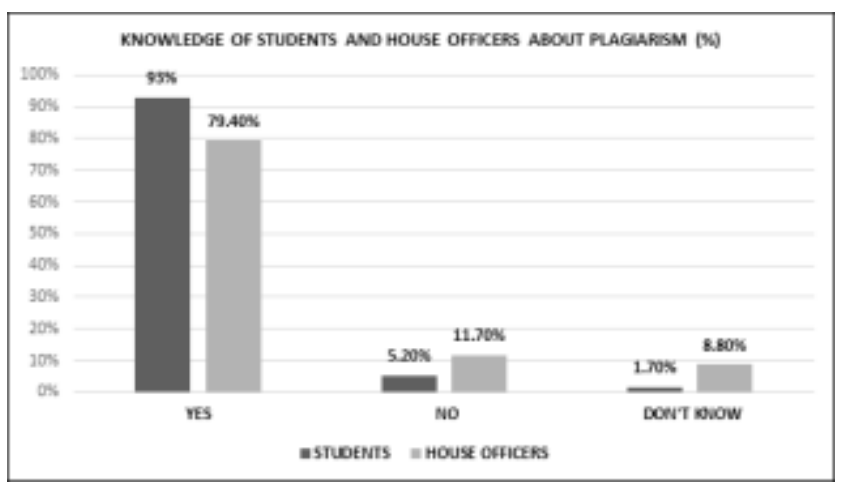

Figure 2: Knowledge of all the participants about plagiarism

assessments and knowledge would improve their writing skills and prevent plagiarism from occurring, while $8.7 \%$ did not and $3.3 \%$ were not aware at all.

\section{Practice}

Majority of the participants (75.3\%) believed that they could manage their topics easily along with having sufficient time to write about the topic $(78 \%)$ with almost equal correspondence among males and females. Similarly, most of the students also believed that increasing the number of assignments would improve their skills regarding plagiarism. However, despite the increased percentage of knowledge regarding plagiarism, $81.3 \%$ of the students believed that they still need some guidance / workshop regarding plagiarism, whereas $14 \%$ considered they had no need for it and $4.7 \%$ did not know. Last but not the least, $82 \%$ of the correspondents agreed that assigned article reading would be important to save them from plagiarism, of which $83.1 \%$ were women and 80.3 were men.

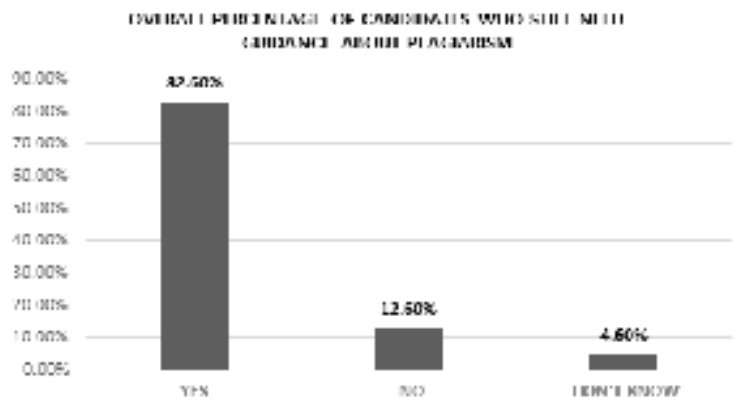

Figure 3: Results of participants still need guidance about plagiarism 
Policies, awareness and outcomes

When they were questioned on whether they were aware of the negative consequences of

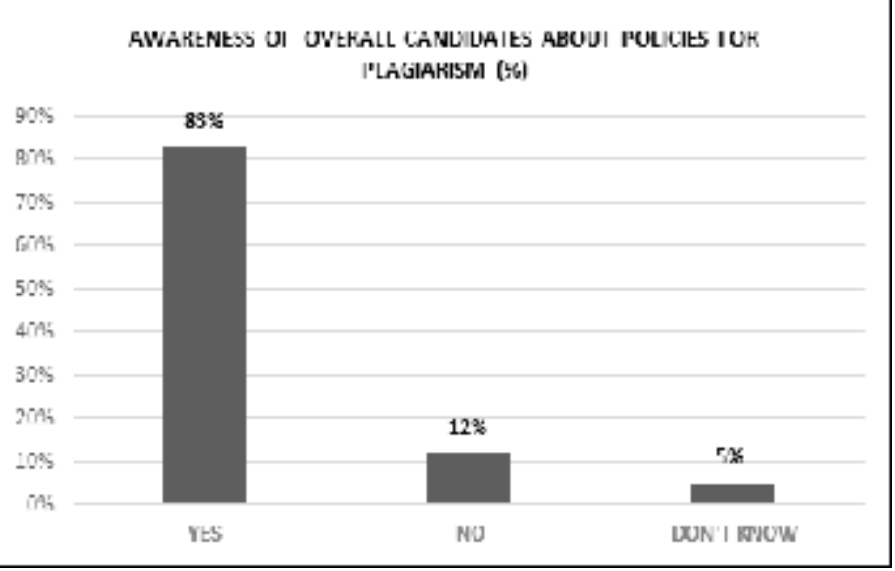

Figure 4: Awareness of plagiarism policies for all the participants

violation, $82.7 \%$ of the respondents agreed to the consequences with a statistical difference

between male $(47 \%)$ and female participants $(77 \%)$. However, $72 \%$ of the participants, both men $(72.1 \%)$ and women $(73 \%))$ equally shared their work with friends before submission and didn't consider it any harm to show their work to others regardless of copying. $82 \%$ of the participants knew submitting a paper written by someone else constitutes academic misconduct, nevertheless, $68 \%$ of them were aware of the college / university policies, systems and procedures for involving plagiarism matter with an increased awareness ratio among men $(70.5 \%)$ compared to females $(66.3 \%)$.

\section{Discussion}

Although limited to one institution, the study sheds light on the nature and extent of the problem that afflicts academia and the student body in Pakistan. The results of our study are, however, reflective of the extent of a problem that exists countrywide within our medical communities. With the help of this questionnaire, we determined the responses of medical students regarding: (i) students' knowledge, (ii) attitudes regarding plagiarism, and (iii) response towards policies and penalties.

Answers to our questionnaire, turned in anonymously, revealed that more than $3 / 4$ of the respondents did not lack knowledge about the most basic principles that constitute plagiarism. Even more better, was our finding that this paucity of knowledge appeared to be equally distributed among medical students and the house officers. These results are in consonance with similar studies conducted previously in Pakistan. The students as compared to house officers faced comparative scores on sufficient knowledge of plagiarism owing to their lack of training in medical writing. Despite of satisfactory results, in Pakistan, at the undergraduate level there is a lack of proper education and training in research methodology and in the medical and publication ethics.
The point of thinking is that, despite of getting knowledge easily, now a day, still, there are some candidates, who don't have knowledge about one of the most important factors. The cause of plagiarism reported highly in students according to one study, (15) due to lack of proper knowledge regarding referencing and citing as reported by $20 \%$ of the participants of our study. Similarly, (16) in one study, conducted on Iranian faculty members reported similar scores. An increased positive attitude towards plagiarism has been in both students and faculty in various international studies, such as in Romania (17-20)

When it came to improving skills and avoiding plagiarism, majority of the participants believed that increasing the number of assignments would improve their skills regarding plagiarism as it would enhance their writing skills. There is evidence to suggest that owing to the lack of language proficiency; most of the students tend to copy word for word from either other people's work or from learning resources (21). Similarly, Ramzan et al., (22) explored this trend in his study and reported lack of awareness of Pakistani university students regarding software for plagiarism detection. Plagiarism can only be decreased once its etiology is properly understood. Majority of the participants $(75.3 \%)$ of the study believed that they had sufficient time to write about the topic. However, in one study, (15) reported that most of the participants confessed to having undergone plagiarism no less than once in life owing to approaching deadlines. As a result, pressure of deadlines has caused the students to focus more on quantity rather than quality. Similarly, in other studies (23-24) conducted in Iran and India respectively reported an increased prevalence of plagiarism owing to pressure to publish, insufficient facilities and lack of funding in institutions.

Despite the increased percentage of knowledge regarding plagiarism, more than $80 \%$ of the participants still believed that they need some guidance / workshop regarding plagiarism. In Pakistan, the obligatory training workshops for trainees and supervisors held at the college and physicians and surgeons do not effectively deal with plagiarism and other medical research and writing unethical practices. Majority of the students in our study believed that they needed formal training in research ethics and medical writing. On the other hand, even though most of the house officers had undergone proper education regarding medical writing and research ethics, they also approved the need to further workshops. It was also observed in our research that the student's year of study had no effect on the attitudes towards plagiarism. Therefore, our hypothesis is approved that formal education and workshops of students could greatly reduce the plagiarism prevalence in Pakistan. On the other hand, there is a vast confusion regarding the evidence of effectiveness of formal education on the attitude towards plagiarism. It was seen in an online case study that adults had no significant association between their incidence of plagiarism and 
formal education regarding policies associated with academic integrity (25). Nevertheless, the frequency of cheating behaviors vastly decreased by imparting knowledge regarding academic honesty policies right before exams (26). In the same way, no significant association was observed by researchers (27) among attending workshops on research ethics and academic fraudulence.

When the participants were questioned regarding the consequences of plagiarism, $82.7 \%$ of the respondents were found to be aware, as mentioned in the above pie chart. Even though $68 \%$ of the participants were aware of their college / university's policies, systems and procedures for involving plagiarism matter, nevertheless, $72 \%$ of the participants equally shared their work with friends before submission.

Based on a study which was conducted in Canada, if caught plagiarizing, the dental staff and students would face punishments ranging from verbal warnings to failing semester (28). Similarly, England also has cases where plagiarists faced strict professional penalties, such as a renowned psychiatrist faced a three-month suspension owing to plagiarism. Even institutions such as Harvard University USA, have reported instances of students and professor's expulsion owing to plagiarism (29).

\section{Conclusion}

Based on our questionnaire, the general attitudes of BMU's students and house officers were found to be positive towards plagiarism. However, there is an insufficiency of training in both biomedical ethics and medical writing. As a part of the under- and postgraduate medical curriculum, education of medical writing and research ethics is lacking. Lack of methods about the awareness are also lacking and not seriously developed and implemented by PMDC, HEC and CPSP.

\section{Recommendations}

Furthermore, to promote a research environment in Pakistan, the revision of undergraduate and postgraduate curriculum should also be considered which could consist of research methodology, referencing and analytical methods.

We also recommend increasing the study data on national level, not only to give awareness about plagiarism but also to prepare the new generation, deal with it properly specially in research and post-graduate level.

\section{Conflict of statement}

Author denies any potential source of conflict statement in the manuscript.

\section{References}

1. Marsh B. The plagiarism debate: History and context. Plagiarism: Alchemy and Remedy in Higher Education. Albany: Suny Press. 2007; pp 31-48

2. Bartley GB, Albert DM, Liesegang TJ. Choosing our words carefully: plagiarism in the internet age. Ophthalmology. 2014; 121: 807-8.

3. Mayden KD. Plagiarism's Poison: Avoiding
Scientific Misconduct. J Adv Pract Oncol. 2015; 6: 77-80.

4. Sinha R, Singh G, Kumar C. Plagiarism and unethical practices in literature. Ind J of Ophth. 2009; 57: 481.

5. Foltynek T, Glendinning I. Impact of Policies for Plagiarism in Higher Education Across Europe: Results of the Project. Acta Universitatis Agriculturae et Silviculturae Mendelianae Brunensis, 2015; 63: 207-216.

6. Yang W. A quantitative study of ESL/EFL students' understanding of plagiarism. Theses and Dissertations (All). 1232. Indiana University of Pennsylvania. 2014

7. Goosney J, Duda D. Avoiding the plagiarism pitfall: Preventing plagiarism in undergraduate research. Teaching Showcase Proceedings.2006; 11: 167-182

8. Ajzen I. The theory of planned behaviour: reactions and reflections. Psychol Health, 2011; 26: 111327.

9. Bamford J, Sergiou K. International students and plagiarism: an analysis of the reasons for plagiarism among international foundation students. Investigations in university teaching and learning, 2005;2: 17-22.

10. Comas-Forgas R, Sureda-Negre J. Academic plagiarism: Explanatory factors from students' perspective. Journal of Academic Ethics, 2010; 8: $217-232$.

11. Glendinning I. Responses to student plagiarism in higher education across Europe. Int $\mathrm{J}$ for Edu Integrity, 2014; 10(1), 4-20

12. Steen RG, Casadevall A, Fang FC. Why has the number of scientific retractions increased? PLoS ONE. 2013; 8(7): e68397

13. Ghias K, Lakho GR, Asim H, Azam IS, Saeed SA. Self-reported attitudes and behaviors of medical students in Pakistan regarding academic misconduct: a cross-sectional study. BMC Med Ethics. 2014; 15(1): 43

14. Ajzen I. The theory of planned behavior. Orgnizational Behavior and Human Decision Processes. 1991; 50: 179-211

15. Shirazi B, Jafarey AM, Moazam F. Plagiarism and the medical fraternity: A study of knowledge and attitudes. J Pak Med Assoc. 2010; 60(4): 269273

16. Ghajarzadeh M, Norouzi-Javidan A, Hassanpour $\mathrm{K}$, Aramesh K, Emami-Razavi SH. Attitude toward plagiarism among Iranian medical faculty members. Acta Medica Iranica. 2012; 50(11): 778-781

17. Badea-Voiculescu O. Attitude of Romanian medicine students towards plagiarism. Romanian J of Morphy and Embryo. 2013; 54(3): 907-908

18. Mavrinac M, Brumini G, Bilic-Zulle L, Petrove M. 
Construction and validation of attitudes toward plagiarism questionnaire. Croatian Med J. 2010; 60(4): 269-273

19. Ghajarzadeh M, Hassanpour K, Fereshtehnejad SM, Jamali A, Nedjat S, Aramesh K. Attitude towards plagiarism among Iranian medical students [Abstract 249]. J of Med Ethics. 2013; 39(4):

20. Hofmann B, Myhr AI, Holm S. Scientific dishonestya nationwide survey of doctoral students in Norway. BMC Med Ethics. 2013; 5(14): 3

21. Vessal K, Habibzadeh F. Rules of the game of scientific writing: fair play and plagiarism. Comment in Lancet. 2007; 369: 641.

22. Ramzan M, Munir MA, Siddique N, Asif M. Awareness about plagiarism amongst university students in Pakistan. High Educ. 2012; 64: 73-84

23. Poorolajal J, Cheraghi P, Doosti Irani A, Cheraghi Z, Mirfakhraei M. Construction of knowledge, attitude and practice questionnaire for assessing plagiarism. Iranian J of Public Health. 2012; 41: 54-58.

24. Singh HP, Guram N. Knowledge and attitude of dental professionals of North India toward plagiarism. North American J of Med Sci. 2014; 6(1): 6-11

25. Jocoy CL, DiBiase D. Plagiarism by adult learners online: a case study in detection and remediation. The Int Review of Res in Open and Distance Learn. 2006; 7(1): 1-15.

26. Kerkvliet J, Sigmund CL. Can we control cheating in the classroom? The $\mathrm{J}$ of Econom Edu Fall. 1999; 30(4): 331-343

27. Anderson MS, Horn AS, Risbey KR, Ronning EA, De Vries R, Martinson BC. What do mentoring and training in the responsible conduct of research have to do with scientists' misbehavior? Findings from a National Survey of $\mathrm{NIH}$-funded scientists. Academic Medicine. 2007; 82(9): 853860

28. Teplitsky PE. Perceptions of Canadian dental faculty and students about appropriate penalties for academic dishonesty. J Dent Educ. 2002; 66: 485-95.

29. Rimer S. When plagiarism's shadow falls on admired scholars. New York Times. 2004; 11. 